\title{
Steady-state mushy layers: experiments and theory
}

\author{
By S. S. L. PEPPIN, P. AUSSILLOUS $\dagger$, \\ HERBERT E. HUPPERT AND M. GRAE WORSTER \\ Institute of Theoretical Geophysics, Department of Applied Mathematics and Theoretical Physics, \\ University of Cambridge, Wilberforce Road, Cambridge CB3 0WA, UK
}

(Received 16 August 2006 and in revised form 15 September 2006)

A new facility has been developed to investigate the directional solidification of transparent aqueous solutions forming mushy layers in a quasi-two-dimensional system. Experiments have been conducted on $\mathrm{NaCl}-\mathrm{H}_{2} \mathrm{O}$ solutions by translating a Hele-Shaw cell at prescribed rates between fixed heat exchangers providing a temperature gradient of approximately $1{ }^{\circ} \mathrm{C} \mathrm{mm}^{-1}$. The mush-liquid interface remained planar at all freezing velocities larger than $8 \mu \mathrm{m} \mathrm{s}^{-1}$, while steepling occurred at lower velocities. No significant undercooling of the mush-liquid interface was detected at freezing velocities up to $12 \mu \mathrm{m} \mathrm{s}^{-1}$. Mathematical predictions of the steadystate temperature profile and mushy-layer thickness as functions of freezing rate are in excellent agreement with experimental measurements.

\section{Introduction}

During solidification of multi-component melts the interface between solid and liquid can become dendritic as the result of a morphological instability (Mullins \& Sekerka 1964). At high freezing rates the dendrites and interstitial fluid form regions of mixed phase referred to as mushy layers (Worster 2000). These regions are present during the solidification of metallic alloys, sea ice, magma and aqueous solutions (Huppert 1990), and they can have profound effects on the physical properties of the resultant solid. For example, convection in the layers can become focused into narrow channels devoid of solid. These channels create defects in metallic alloys (Copley et al. 1970) and are believed to be important in the dynamics of sea ice (Wettlaufer, Worster \& Huppert 1997) and the evolution of the Earth's core (Bergman \& Fearn 1994).

Huppert \& Worster (1985) and Worster (1986) developed and solved mathematical models describing mushy layers and compared the results to experiments in which transient non-convecting mushy layers were grown from a chilled plate. Many experiments have also been conducted in which compositional convection stimulated the development of chimneys (Copley et al. 1970; Sarazin \& Hellawell 1988; Chen \& Chen 1991; Tait \& Jaupart 1992; Huppert \& Hallworth 1993; Chen 1995; Wettlaufer et al. 1997; Solomon \& Hartley 1998; Aussillous et al. 2006). All of these experiments were performed under transient conditions. 

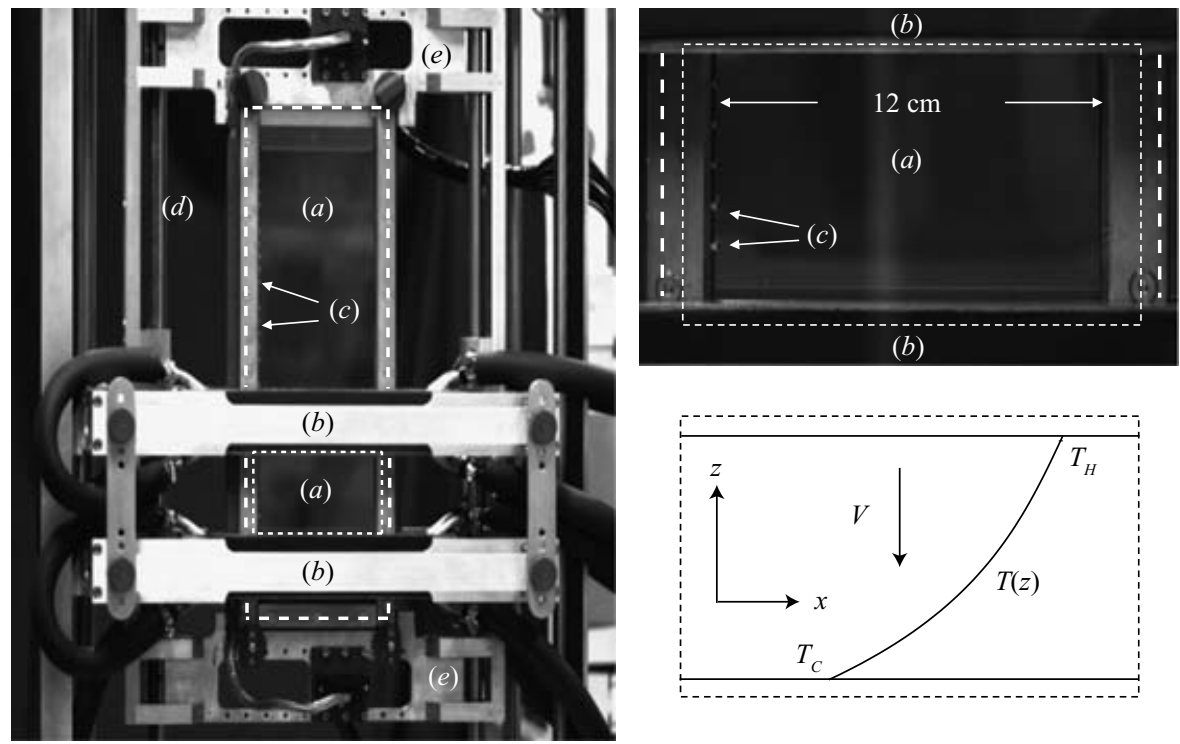

FIGURE 1. Photograph of a unidirectional solidification stage including (a) Hele-Shaw cell, $(b)$ heat exchangers, $(c)$ thermistors, $(d)$ machined screw to stepper motor, and $(e)$ aluminium frame. The entire apparatus was maintained in a sealed cabinet through which dry air was pumped to prevent condensation on the test cell. The region of interest between the two heat exchangers is shown magnified at the upper right. Also shown is a schematic diagram illustrating the coordinate system used in the analysis and a representative temperature profile.

In contrast, many mathematical analyses of buoyancy-driven instabilities and developed convection in mushy layers have considered a steady-state casting configuration in which the sample is pulled at a constant rate through a fixed temperature gradient (Hills, Loper \& Roberts 1983; Fowler 1985; Worster 1991; Worster 1992; Schulze \& Worster 1999; Loper \& Roberts 2001; Chung \& Worster 2002). Detailed predictions have been made and there is a need for corresponding experimental measurements.

Here we report on results obtained with a new experimental facility that has been specifically developed to investigate steady-state dynamics in mushy layers formed from aqueous solutions. In this paper we establish the steady, diffusively controlled, non-convecting state as a basis for future studies of steadily driven convection in mushy layers. In $\S 2$ we describe the facility and characterize its thermal properties. Then in $\S 3$ we present the results of a series of experiments on aqueous solutions of sodium chloride. A mathematical model of the system is developed and solved in $\S 4$, and quantitative comparisons with experiment are made in $\S 5$. A discussion of the results and implications for future experiments is also given.

\section{Experimental apparatus}

\subsection{Description}

The experimental apparatus consists of a Hele-Shaw cell - a fluid-filled rectangular cell whose depth is much smaller than its height and width (Batchelor 1967) - held in an aluminium frame as depicted in figure 1 . The Hele-Shaw cell has inner dimensions of $38 \times 12 \times 0.5 \mathrm{~cm}$ between $2 \mathrm{~mm}$ thick Pyrex glass plates. Thermistors are embedded in the side of the cell where they make direct contact with the liquid or mushy layer. 
In some experiments an independent thermistor was also placed near the centre of the cell. After loading the cell in the aluminium frame, copper heat exchangers were placed against the glass plates and held by spring-loaded brass screws. The temperature of the heat exchangers is maintained by pumping ethylene glycol through the upper exchanger and methanol through the lower one. Methanol is used because ethylene glycol becomes too viscous at temperatures below $-30^{\circ} \mathrm{C}$. The cell is moved by a Smartdrive Taranis stepper motor having microstep resolution of 51200 steps per revolution and $0.88 \mathrm{Nm}$ holding torque, coupled with a 100/1 gearbox. The machine screw has a pitch of $1.5 \mathrm{~mm}$ yielding approximately 5000 motor steps per $\mu \mathrm{m}$. The entire apparatus is maintained in a sealed cabinet $(120 \times 90 \times 60 \mathrm{~cm})$ through which dry air is pumped to prevent condensation. An experiment is initiated by allowing the pre-cooled refridgerant to enter the heat exchangers. After the temperature field stabilizes, the cell is translated downward at a constant rate $V$. During the experiment, thermistor readings and time-lapse digital images of the test cell are recorded by a computer.

\subsection{Thermal characterization}

In unidirectional solidification stages where the freezing area is small and wellinsulated it can often be assumed that the temperature profile between the heat exchangers is linear (Rubinsky \& Ikeda 1985). In the present case, however, the Hele-Shaw cell is left open to the environment of the cabinet and significant heat transfer occurs both through and along the Pyrex glass. It was therefore essential to characterize the thermal properties of the cell before attempting mathematical modelling of the solidification process. To determine these properties a series of experiments was conducted on pure water with the lower heat exchanger at $5{ }^{\circ} \mathrm{C}$ and the upper at $20^{\circ} \mathrm{C}$.

In order to account for heat flow from the cabinet to the cell, we model the cell as a cooling fin and use Newton's law of cooling with a coefficient $b$ through the equation

$$
\frac{\mathrm{d} q_{h}}{\mathrm{~d} z}=b\left(T-T_{\infty}\right),
$$

where $q_{h}$ is the heat flux through the sides of the cell and $T_{\infty}$ (typically between 20 and $21^{\circ} \mathrm{C}$ ) is the temperature of the dry air in the cabinet. The coefficient $b$ is related to the heat transfer coefficient $h_{T}$ by the relation $b=h_{T} P / A$, where $P=25.8 \mathrm{~cm}$ is the perimeter and $A=10.8 \mathrm{~cm}^{2}$ the area of a cross-section of the Hele-Shaw cell (Incropera $\&$ Dewitt 1996). Owing to the different thermal conductivities and heat capacities of glass and water, there is additional heat flow down through the Pyrex sides of the cell between the heat exchangers. To account for this three-dimensional heat flow and still allow one-dimensional modelling we define effective thermal conductivities and volumetric heat capacities as areal averages of those of Pyrex and pure water:

$$
k_{l}=\zeta k_{w}+(1-\zeta) k_{p}, \quad c_{l}=\zeta c_{w}+(1-\zeta) c_{p},
$$

where $\zeta=5 / 9$ is the fraction of the cross-sectional area of the Hele-Shaw cell occupied by water, $1-\zeta$ is the fraction occupied by the Pyrex glass, $k$ is thermal conductivity, $c$ is heat capacity per unit volume, and the subscripts ' $w$ ' and ' $p$ ' denote properties of the water and Pyrex, respectively. Conservation of energy at steady state can then be written as

$$
-c_{l} V \frac{\mathrm{d} T}{\mathrm{~d} z}=k_{l} \frac{\mathrm{d}^{2} T}{\mathrm{~d} z^{2}}-b\left(T-T_{\infty}\right) .
$$



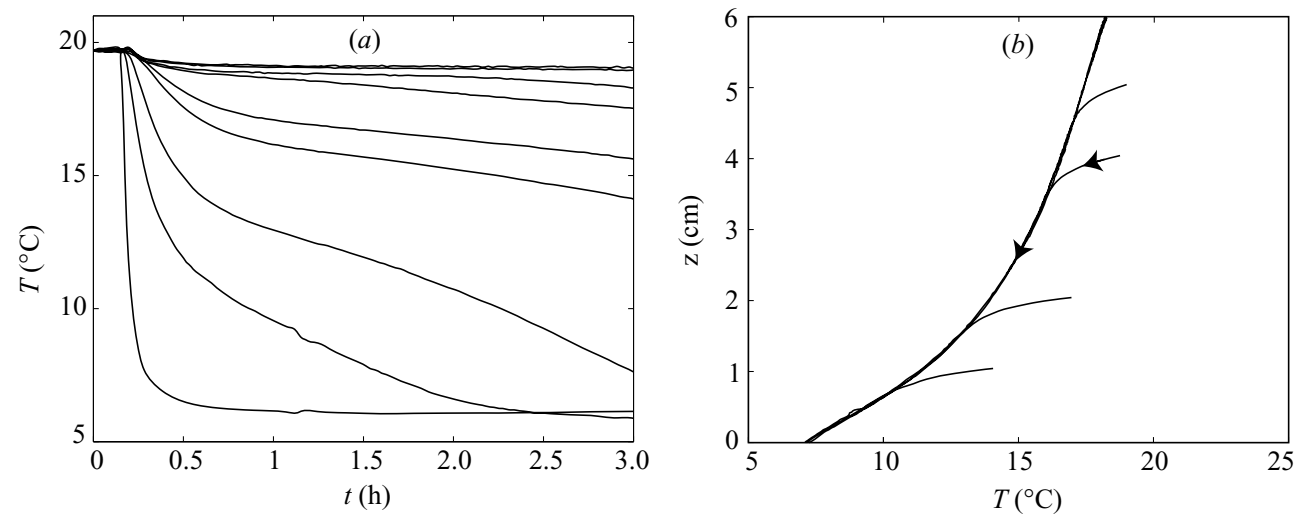

Figure 2. (a) Temperature-time curves measured by the different thermistors at the side of the cell. $(b)$ Plot of the temperature data in the form $T(t)$ versus $z(t)$, where $z(t)=p_{0}-V t$ and $p_{0}$ is the initial position of the thermistors. The arrows point in the direction of increasing time. Thermal steady state occurs when the data all collapse onto a single curve. This takes approximately 30 minutes.

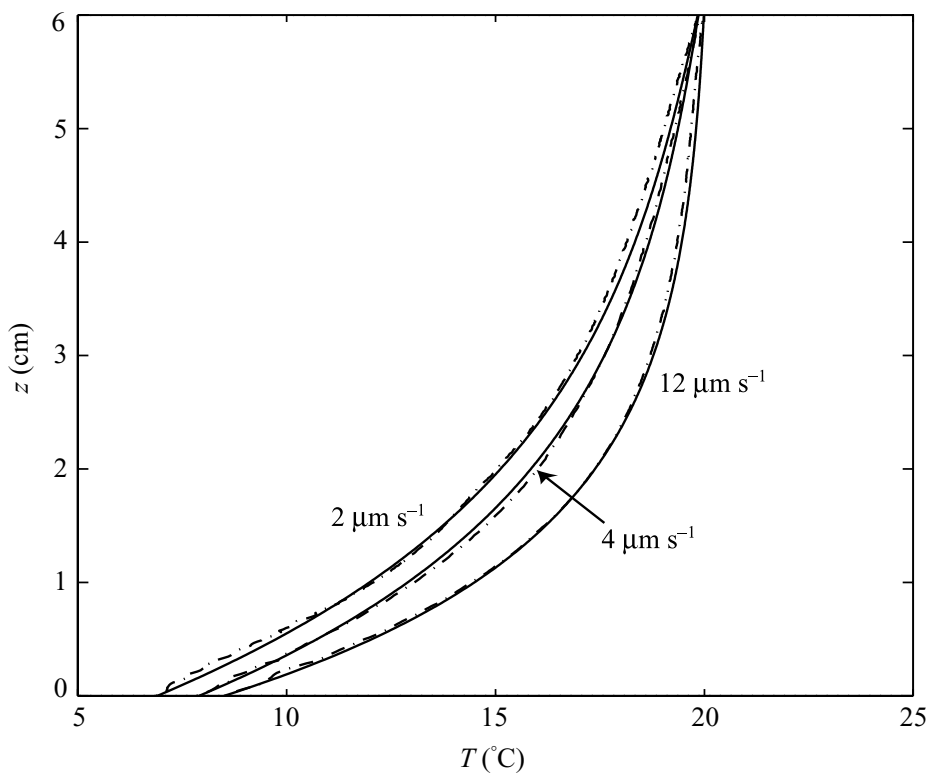

FIGURE 3. Temperature profiles (dot-dashed lines) measured at the centre of the cell during steady translation with the heat exchangers at $5^{\circ} \mathrm{C}$ and $20^{\circ} \mathrm{C}$. The solid lines are from equation (2.4) with the coefficient $b$ chosen to fit the data.

Given boundary conditions $T(0)=T_{C}$ and $T(L)=T_{H}$, where $L=6 \mathrm{~cm}$ is the separation between the heat exchangers, equation (2.3) can readily be solved analytically to give

$$
T(z)=T_{\infty}+\frac{\left(T_{H}-T_{\infty}\right)\left(\mathrm{e}^{r_{1} z}-\mathrm{e}^{r_{2} z}\right)+\left(T_{C}-T_{\infty}\right)\left(\mathrm{e}^{r_{1} L+r_{2} z}-\mathrm{e}^{r_{2} L+r_{1} z}\right)}{\mathrm{e}^{r_{1} L}-\mathrm{e}^{r_{2} L}},
$$

where $r_{1,2}=-\frac{1}{2} \mathscr{V} \pm \frac{1}{2} \sqrt{\mathscr{V}^{2}+4 b / k_{l}}$ and $\mathscr{V}=V c_{l} / k_{l}$.

Experimentally, thermal steady state was achieved when the temperature profiles measured by the thermistors (figure $2 a$ ) collapsed onto a single curve when plotted versus position between the heat exchangers (figure $2 b$ ). Figure 3 shows plots of 


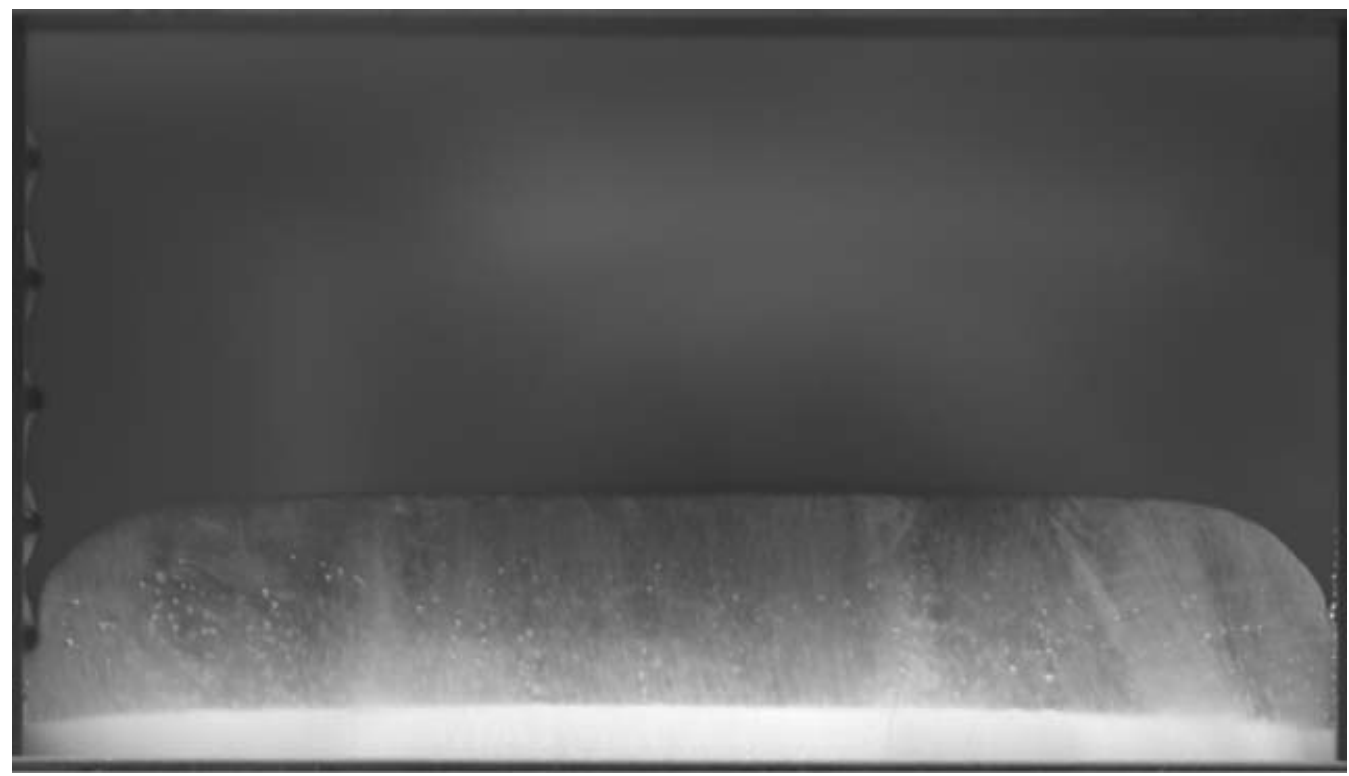

Figure 4. Mushy layer with ice as the solid phase formed during the solidification of a $3.5 \mathrm{wt} \% \mathrm{NaCl}$ solution at $1 \mu \mathrm{m} / \mathrm{s}$. The white solid at the bottom is the eutectic. The distance between the thermistors, seen at the left, is $1 \mathrm{~cm}$.

the experimental steady-state temperature profiles for cell velocities ranging from 2 to $12 \mu \mathrm{m} \mathrm{s}^{-1}$, along with the profiles given by (2.4). A single coefficient $b=$ $1600 \mathrm{~J} \mathrm{~m}^{-3} \mathrm{~s}^{-1} \mathrm{~K}^{-1}$, corresponding to a heat transfer coefficient $h_{T}=6.7 \mathrm{~J} \mathrm{~m}^{-3} \mathrm{~s}^{-1} \mathrm{~K}^{-1}$, yields a very good fit of all the data. This coefficient is used in the analysis of all our subsequent experiments.

\section{Experiments with aqueous solutions of sodium chloride}

In our experiments, we used three different concentrations, 3.5, 7 and $14 \mathrm{wt} \%$ of $\mathrm{NaCl}$ in water and studied a range of pulling speeds from 0.5 to $12 \mu \mathrm{m} \mathrm{s}^{-1}$. The temperature of the fluid pumped through the lower and upper heat exchangers was held at $-38^{\circ} \mathrm{C}$ and $20^{\circ} \mathrm{C}$, respectively. The actual temperature measured by thermistors in the cell as they passed through the middle of the lower heat exchanger was about $-27^{\circ} \mathrm{C}$. The temperature of the lower heat exchanger was chosen to ensure that the eutectic, which forms at $-21.2^{\circ} \mathrm{C}$, was observed at all pulling speeds. After allowing the coolant to enter the heat exchangers, the mushy layer was permitted to grow diffusively until the temperature profile stabilized, which took approximately 1 hour. Thereafter the cell was translated at a fixed velocity. Once thermal steady state had been achieved, steady-state for the mushy layer was taken to be the point at which the thickness of the mushy layer stopped changing with time. Aqueous $\mathrm{NaCl}$ was used in the experiments because the rejected solute is more dense than the solution, promoting stability with respect to buoyancy-driven convection. Nevertheless, as will be seen, the solidification front did not always remain planar and some convection did occur.

Figure 4 shows a mushy layer that formed during the solidification of a $3.5 \mathrm{wt} \%$ solution translated at $1 \mu \mathrm{m} \mathrm{s}^{-1}$. The eutectic is visible as the dense white solid just above the lower heat exchanger. Near the edges of the Hele-Shaw cell, the 
mush-solution interface is highly curved. A possible explanation for the curvature is heat transfer through the edges of the cell. If this were the sole cause, the mushsolution interface would follow lines of constant temperature. However, within the highly curved regions the interface temperature rapidly decreases, indicating that some other process in addition to heat transfer is responsible. The depression of the sides of the mushy layer may be related to steepling, a phenomenon in which a convective flow moves dense solution toward depressions in the interface (Burden, Hebditch \& Hunt 1973). Pools of dense fluid could be observed collecting in the curved regions during the experiments. It is generally thought that steepling is due to a long-wavelength instability of the planar freezing front (Coriell \& McFadden 1989; Brattkus 1995). While we observed steepling in all experiments at speeds below about $8 \mu \mathrm{m} \mathrm{s}^{-1}$, the thickness of the mushy layer at the centre of the cell was unaffected, at least for speeds higher than $0.5 \mu \mathrm{m} \mathrm{s}^{-1}$. That is, the temperature at the interface between the mushy layer and solution at the centre of the cell remained at the liquidus temperature of the bulk solution at all speeds tested, to within experimental error.

\section{Theoretical development}

As discussed by Huppert \& Worster (1985), most of the solute rejected by the growing ice crystals accumulates within the mushy layer, in which case the concentration of solute remains almost constant in the liquid ahead of the mushy layer. We assume that $\mathrm{NaCl}$ has zero solubility in ice, and neglect diffusion within the mushy layer. This should be valid in aqueous systems for which the ratio of the mass diffusivity to the thermal diffusivity is small (Worster 2000). Finally, we assume that steepling does not affect the properties of the mushy layer at the centre of the cell where our measurements are made. At steady state, conservation of energy in the liquid region is then given by equation (2.3), with boundary conditions $T(h)=T_{m}-\Gamma C_{0}$ and $T(L)=T_{\infty}=20^{\circ} \mathrm{C}$, where $T_{m}=0{ }^{\circ} \mathrm{C}$ is the freezing temperature of pure water, $h$ is the steady-state thickness of the mushy layer, $-\Gamma$ is the slope of the freezing temperature curve (liquidus) and $C_{0}$ is the solute mass fraction in the liquid ahead of the mushy layer.

Equations describing conservation of energy and mass within the mushy layer have been derived by Hills et al. (1983) and Worster (1986). When modified to account for heat transfer through the sides of the Hele-Shaw cell the equations governing steady states are

$$
\begin{gathered}
-c_{l} V \frac{\mathrm{d} T}{\mathrm{~d} z}=\frac{\mathrm{d}}{\mathrm{d} z} k_{e} \frac{\mathrm{d} T}{\mathrm{~d} z}-\zeta \mathscr{L}_{s} V \frac{\mathrm{d} \phi}{\mathrm{d} z}-b\left(T-T_{\infty}\right), \quad 0 \leqslant z \leqslant h, \\
(1-\phi) \frac{\mathrm{d} C}{\mathrm{~d} z}=C \frac{\mathrm{d} \phi}{\mathrm{d} z}, \quad 0 \leqslant z \leqslant h,
\end{gathered}
$$

where $\phi$ is the volume fraction of ice in the mushy layer, $\mathscr{L}_{s}$ is the latent heat per unit volume of ice and $C$ is the mass fraction of solute in the interstitial liquid, related to $T$ by the local equilibrium liquidus condition

$$
T(z)=T_{m}-\Gamma C(z), \quad 0 \leqslant z \leqslant h .
$$

The effective thermal conductivity is given by the expression $k_{e}=\zeta k_{m}+(1-\zeta) k_{p}$, where $k_{m}=\phi k_{s}+(1-\phi) k_{w}$ is the thermal conductivity of the mushy layer.

Using the boundary conditions $\phi(h)=0$ and $T(h)=T_{m}-\Gamma C_{0}$, we combine (4.2) with (4.3) and integrate the result to yield

$$
\phi(z)=1+\Gamma C_{0} / T(z), \quad 0 \leqslant z \leqslant h .
$$




\begin{tabular}{lccllcc}
\hline \multicolumn{1}{c}{ Quantity } & Symbol & Value & Quantity & Symbol & Value \\
Thermal conductivity (water) & $k_{w}$ & $0.54 \mathrm{~J} \mathrm{~m}^{-1} \mathrm{~s}^{-1} \mathrm{~K}^{-1}$ & Density (water) & $\rho_{w}$ & $1000 \mathrm{~kg} \mathrm{~m}^{-3}$ \\
Thermal conductivity (ice) & $k_{i}$ & $2.2 \mathrm{~J} \mathrm{~m}^{-1} \mathrm{~s}^{-1} \mathrm{~K}^{-1}$ & Density (ice) & $\rho_{i}$ & $920 \mathrm{~kg} \mathrm{~m}^{-3}$ \\
Thermal conductivity (Pyrex) & $k_{p}$ & $1.1 \mathrm{~J} \mathrm{~m}^{-1} \mathrm{~s}^{-1} \mathrm{~K}^{-1}$ & Density (Pyrex) & $\rho_{p}$ & $2230 \mathrm{~kg} \mathrm{~m}^{-3}$ \\
Specific heat capacity (water) & $c_{p w}$ & $4184 \mathrm{~J} \mathrm{~kg}^{-1} \mathrm{~K}^{-1}$ & Heat of fusion & $L_{f}$ & $3.3 \times 10^{5} \mathrm{~J} \mathrm{~kg}^{-1}$ \\
Specific heat capacity (ice) & $c_{p i}$ & $2100 \mathrm{~J} \mathrm{~kg}^{-1} \mathrm{~K}^{-1}$ & Liquidus slope & $\Gamma$ & $0.7^{\circ} \mathrm{C} / \mathrm{wt} \%$ \\
Specific heat capacity (Pyrex) & $c_{p p}$ & $753 \mathrm{~J} \mathrm{~kg}^{-1} \mathrm{~K}^{-1}$ & Eutectic temp & $T_{e}$ & $-21.2^{\circ} \mathrm{C}$
\end{tabular}

TABLE 1. Physical property values used in the theoretical calculations.

Inserting (4.4) into (4.1), we obtain

$$
\frac{\mathrm{d}}{\mathrm{d} z} k_{e} \frac{\mathrm{d} T}{\mathrm{~d} z}=-\left(\frac{\zeta \mathscr{L}_{s} V \Gamma C_{0}}{T^{2}}+V c_{l e}\right) \frac{\mathrm{d} T}{\mathrm{~d} z}+b\left(T-T_{\infty}\right), \quad 0 \leqslant z \leqslant h,
$$

as the equation governing the temperature field in the mushy layer. The boundary conditions for equation (4.5) are

$$
T(0)=T_{e}, \quad T(h)=T_{m}-\Gamma C_{0},\left.\quad \frac{\mathrm{d} T}{\mathrm{~d} z}\right|_{h^{-}}=\left.\frac{\mathrm{d} T}{\mathrm{~d} z}\right|_{h^{+}},
$$

where $T_{e}=-21.2{ }^{\circ} \mathrm{C}$ is the eutectic temperature and $T_{z}\left(h^{+}\right)$is obtained from the solution to (2.3). Equations (4.5) and (4.6) were solved numerically using a standard shooting method (Press et al. 1992). Values for $h$ and $T_{z}(0)$ were guessed initially and equation (4.5) was solved numerically as an initial value problem for $T(h)$ and $T_{z}(h)$. Newton's method was then used to estimate new values for $h$ and $T_{z}(0)$, and the procedure was repeated until the predicted boundary conditions at $z=h$ agreed with the known values in (4.6).

\section{Results and discussion}

The model described in $\S 4$ was solved using parameters relevant to $\mathrm{NaCl}-$ $\mathrm{H}_{2} \mathrm{O}$ solutions, as listed in table 1. Figure 5(a) shows plots of the predicted steady-state temperature profiles at freezing velocities of $2 \mu \mathrm{m} / \mathrm{s}$ and $6 \mu \mathrm{m} / \mathrm{s}$, along with the experimentally measured profiles. The plots are nonlinear, owing to the combined influence of heat transfer from the sides, the finite velocity of the cell, the differing thermal conductivities and the release of latent heat within the mushy layer. Nevertheless, one-dimensional modelling with the heat transfer coefficient determined in $\S 2.2$ yields good reproduction of the measured temperature profiles. In figure $5(b)$ we plot the measured height of the mushy layer versus the freezing velocity for all of the experiments, along with the predictions of $h$ from (4.5) and (4.6). Again there is excellent agreement between the predicted and measured results.

The temperature at the mush-solution interface is always below the liquidus temperature of the bulk solution owing to a thin boundary layer of rejected solute (Worster 1986). In convecting systems this can lead to significant undercoolings at the interface (Worster \& Kerr 1994). In the absence of convection, and in the case of ice growing orthogonal to its c-axis, the undercooling should be small. The circles in figure $5(a)$ represent the measured position of the steady-state mushy-layer interface at the centre of the cell, while the dashed line represents the liquidus temperature of the bulk solution. To within experimental error, the temperature at the top of the mushy layer corresponds to the liquidus temperature at all speeds. The temperature gradient at the 

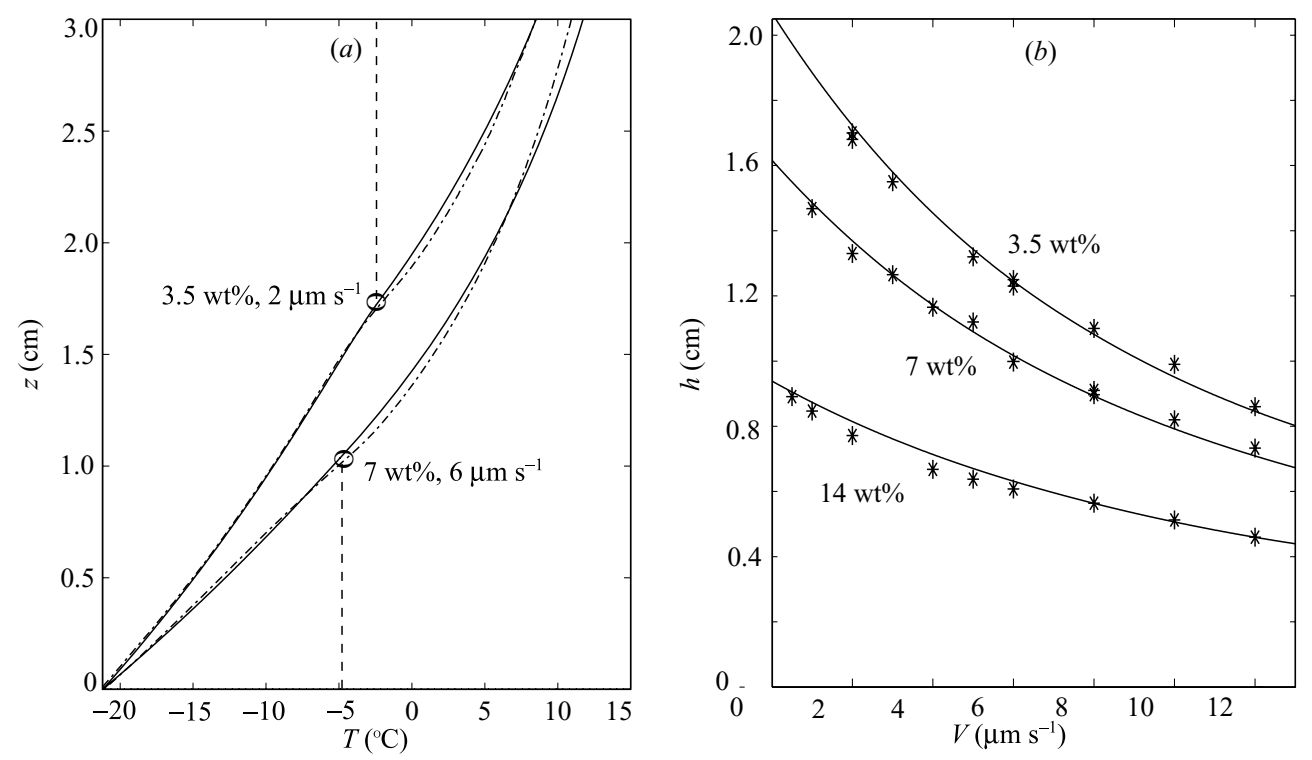

FIGURE 5. (a) Measured (dash-dot lines) and predicted (solid lines) temperature profiles during solidification of $3.5 \mathrm{wt} \%$ and $7 \mathrm{wt} \%$ solutions at $2 \mu \mathrm{m} \mathrm{s}^{-1}$ and $6 \mu \mathrm{m} \mathrm{s}^{-1}$, respectively. (b) Measured $(*)$ and predicted (curves) heights of the mushy layer as functions of the freezing velocity.

mush-liquid interface was relatively large, however, particularly at high pulling speeds, and it is conceivable that undercoolings did exist but were not resolvable with our thermistors. Future studies employing smaller thermistors and a shallower temperature gradient could be used to determine the actual undercooling at the interface.

\section{Conclusion}

A new facility has been developed to investigate the directional solidification of an aqueous binary melt. The apparatus allows independent variations in the solidification rate and applied temperature gradient. By using transparent aqueous solutions it has been possible to monitor the evolution of mushy layers, and to obtain accurate temperature measurements. This has considerable advantages over studies with metallic alloys requiring much higher temperatures and care in their use. Although some buoyancy-driven flow resulted in a form of steepling, one-dimensional mathematical models of the steady-state temperature profile and mushy-layer height accurately predict the experimental results.

We are grateful to D. Page-Croft for the engineering design of the apparatus. We are indebted to him, M. A. Hallworth, J. Milton, T. Parker and R. Raincock for the construction of this extremely high-quality experimental facility. We also thank $\mathrm{M}$. A. Hallworth for technical assistance with the experiments. This research was funded by a grant from the Leverhulme Trust. H.E.H.'s research is supported by a Royal Society Wolfson Merit Award.

\section{REFERENCES}

Aussillous, P., Sederman, A. J., Gladden, L. F., Huppert, H. E. \& Worster, M. G. 2006 Magnetic resonance imaging of structure and convection in solidifying mushy layers. J. Fluid Mech. 552, 99-125. 
Batchelor, G. K. 1967 An Introduction to Fluid Dynamics Cambridge University Press.

Bergman, M. I. \& Fearn, D. R. 1994 Chimneys on the Earth's inner-outer core boundary? Geophys. Res. Lett. 21, 477-480.

BrattKus, K. 1995 Directional solidification into static stability. J. Fluid Mech. 304, 143-159.

Burden, M. H., Hebditch, D. J. \& Hunt, J. D. 1973 Macroscopic stability of a planar, cellular or dendritic interface during directional freezing. J. Cryst. Growth 20, 121-124.

Chen, C. F. 1991 Experimental study of convection in a mushy layer during directional solidification. J. Fluid Mech. 293, 81-98.

Chen, F. \& CHen, C. F. 1991 Experimental study of directional solidification of aqueous ammonium chloride solution. J. Fluid Mech. 227, 567-586.

Chung, C.-A. \& Worster, M. G. 2002 Steady state chimneys in a mushy layer. J. Fluid Mech. 455, 387-411.

Copley, S. M., Giamei, A. F., Johnson, S. M. \& Hornbecker, M. F. 1970 The origin of freckles in unidirectionally solidified castings. Metall. Trans. 1, 2193-2204.

Coriell, S. R. \& McFadden, G. B. 1989 Buoyancy effects on morphological instability during directional solidification. J. Cryst. Growth 94, 513-521.

Fowler, A. C. 1985 The formation of freckles in binary alloys. IMA J. Appl. Maths 35, 159-174.

Hills, R. N., Loper, D. E. \& Roberts, P. H. 1983 A thermodynamically consistent model of a mushy zone. Q. J. Mech. Appl. Maths 36, 505-539.

Huppert, H. E. 1990 The fluid mechanics of solidification. J. Fluid Mech. 212, 209-240.

Huppert, H. E. \& Hallworth, M. A. 1993 Solidification of $\mathrm{NH} 4 \mathrm{Cl}$ and NH4Br from aqueous solutions contaminated with CuSO4: the extinction of chimneys. J. Cryst. Growth 130, 495506.

Huppert, H. E. \& Worster, M. G. 1985 Dynamic solidification of a binary melt. Nature 314, 703-707.

Incropera, F. P. \& DeWitt, D. P. 1996 Fundamentals of Heat and Mass Transfer, 4th Edn. John Wiley \& Sons.

Loper, D. E. \& Roberts, P. H. 2001 Mush-chimney convection. Stud. Appl. Maths 106, 187-227.

Mullins, W. W. \& Sekerka, R. F. 1964 Stability of a planar interface during solidification of a dilute binary alloy. J. Appl. Phys. 35, 444-451.

Press, W. H., Teukolsky, S. A., Vetterling, W. T. \& Flannery, B. P. 1992 Numerical Recipes in $C, 2$ nd Edn. Cambridge University Press.

RuBinsKy, B. \& IKEDA, M. 1985 A cryomicroscope using directional solidification for the controlled freezing of biological material. Cryobiology 22, 55-68.

Sarazin, J. R. \& Hellawell, A. 1998 Channel formation in $\mathrm{Pb}-\mathrm{Sn}, \mathrm{Pb}-\mathrm{Sb}$ and $\mathrm{Pb}-\mathrm{Sn}-\mathrm{Sb}$ alloys and comparison with the system NH4Cl-H20. Metall. Trans. 19A, 1861-1871.

Schulze, T. M. \& Worster, M. G. 1999 Weak convection, liquid inclusions and the formation of chimneys in mushy layers. J. Fluid Mech. 388, 197-215.

Solomon, T. H. \& HartLey, R. R. 1998 Measurements of the temperature field of mushy and liquid regions during solidification of aqueous ammonium chloride. J. Fluid Mech. 358, 87-106.

TAIT, S. \& JAUPART, C. 1992 Compositional convection in a reactive crystalline mush and melt differentiation. J. Geophys. Res. 97, 6735-6756.

Wettlaufer, J. S., Worster, M. G. \& Huppert H. E. 1997 Natural convection during solidification of an alloy from above with application to the evolution of sea ice. J. Fluid Mech. 344, 291-316.

Worster, M. G. 1986 Solidification of an alloy from a cooled boundary. J. Fluid Mech. 167, 481-501.

Worster, M. G. 1991 Natural convection in a mushy layer. J. Fluid Mech. 224, 335-359.

Worster, M. G. 1992 Instabilities of the liquid and mushy regions during solidification of alloys. J. Fluid Mech. 237, 649-669.

Worster, M. G. 2000 Solidification of fluids. In Perspectives in Fluid Dynamics (ed. G. K. Batchelor, H. K. Moffatt \& M. G. Worster), pp. 393-446. Cambridge University Press.

Worster, M. G. \& KerR, R. C. 1994 The transient behaviour of alloys solidified from below prior to the formation of chimneys. J. Fluid Mech. 269, 23-44. 